\title{
AS ÁGUAS TERMAIS DE POÇOS DE CALDAS, MG - ESTUDO EXPERIMENTAL DAS INTERAÇÕES ÁGUA-ROCHA
}

\author{
WALDEMIR BARBOSA DA CRUZ* C CARLOS ALBERTO DE MELLO PEIXOTO*
}

\begin{abstract}
THE TERMAL WATER OF POÇOS DE CALDAS, MG - AN EXPERIMENTAL STUDY OF WATER-ROCK INTERACTIONS The solubility and reactivity of the Pocos de Caldas alcaline complex were study under laboratory conditions. The objective was to identify its contribution to the groundwater mineralization process. Samples of foyaite, phonolite, brecciated tinguaite, and "filling vein material" were ground and soaked in water under several temperature and $\mathrm{pH}$. For different contact time (from 8 to 1,176 hours), the resulting solutions were analysed to verify the proportion of extraction from the parent material. The composition of the resulting solutions were compared to the groundwater specially the termal waters. The study resuIts showed a strong relationship between groundwater composition and the laboratory solutions. Reactivity was strongest for the foyaites, followed by tinguaites, and in a smaller scale by the phonolites and the "filling vein materiai".
\end{abstract}

\begin{abstract}
RESUMO AS ÁGUAS TERMAIS DE POÇOS DE CALDAS, MG - ESTUDO EXPERIMENTAL DAS INTERAÇÖES ÁGUA-ROCHA Com o objetivo de verificar o grau de solubilidade ou de reatividade das rochas do complexo alcalino de Poços de Caldas, foram realizados alguns experimentos, sob condiçóes controladas em laboratório, visando conhecer a contribuição dessas rochas à mineralização das águas subterrâneas. Quatro tipos de materiais - foiaíto, fonólito, tinguaíto brechado e material de preenchimento de veio - foram coletados e, em seguida, triturados e imersos èm água sob diversas condiçōes de temperatura e $\mathrm{pH}$. As soluçóes resultantes para diferentes tempos ( de oito a 1.176 horas) foram analisadas a fim de verificar a proporção na qual os vários elementos foram liberados das rochas. A composição das soluçôes experimentais foi comparada com a das águas subterrâneas, em especial com as águas termais. Os resultados inđicam que há grande correspondência entre a composiçăo đas soluçōes de reaçōes obtidas em laboratório e as águas subterrâneas, sendo o foiaíto a rocha mais reativa, seguida do tínguaf́to e em menor proporção o fonólito e o material de preenchimento de veio.
\end{abstract}

INTRODUÇÃO No estudo de muitos sistemas hidrotermais, a concentração na água dos maiores constituintes das rochas, tais como sódio, potássio, cálcio e silício, tem sido reconhecida como sendo influenciada pela interação água-rocha. Ao contrário, elementos em menores concentraçốes em rochas ígneas, como cloro, flúor, boro e nitrogênio, têm sido mais comumente referidos como originados de fluidos magmáticos profundos, . sem primeiro testar adequadamente se eles podem ser derivados de simples interação água-rocha em níveis mais superficiais (Ellis \& Mahon 1964).

É comum, também, em áreas de vulcanismo antigo considerar-se a ocorrência de águas termais como inequívoca manifestação tardia do fenômeno. Por outro lado, na identificação da procedência dos constituintes da água, não se faz diferença, muitas vezes, entre a origem primária dos elementos e o modo como foi incorporado à água.

O estudo hidrogeológico e liïdroquímico dos arredores de Poços de Caldas, efetuado pela Fundação Centro Tecnológico de Minas Gerais (Cetec) para a Prefeitura Municipal (Cruz et al. 1987), mostrou que a evolução da composição química das águas subterrâneas seria influenciada principalmente pelos processos de lixiviação das rochas ígneas e vulcânicas que compöem o complexo. alcalino. Nesta regiâo, a presença de falhas e fraturas profundas e abertas criou condiçôes para a infiltração de águas meteóricas e para a formação de águas termais em meio fissurado, cuja composição não é relacionada a nenhuma manifestação tardia de processos vulcânicos ou magmáticos profundos, mas é determinada exclusivamente por processos de lixiviação das rochas.

Com o objetivo de verificar o grau de solubilidade ou de reatividade da rocha com a água, foram realizados alguns experimentos, sob condiçôes controladas em laboratório, visando conhecer a contribuição à salinização das águas dos diferentes tipos de rocha do Complexo Alcalino.

Além de investigar os processos de solubilização de determinados constituintes das águas subterrâneas, por lixiviação, buscou-se verificar a mobilidade de alguns elementos, especialmente os íons metálicos, e a facilidade com que podem ser incorporados às águas da regiâo.

TRABALHOS ANTERIORES Inúmeros trabalhos foram realizados nos últimos anos sobre as interaçōes água-rocha visando identificar os processos de mineralização e a origem dos constituintes das águas subterrâneas.

Basharina (1958) extraiu muitos constituintes solúveis em água de uma cinza do vulcẫo Bezymiany (in Ellis \& Mahon 1964). A interação de soluçōes cloretadas e sulfatadas ácidas, a $100^{\circ} \mathrm{C}$, com os basaltos Kamchatka, andesitos e dacitos foi examinada por Naboko \& Silnichenko (1960). As concentrações dos maiores constituintes da rocha lixiviados pela solução dependem mais do $\mathrm{Ph}$ que da composição das rochas. Os experimentos forneceram um modelo razoável para explicar as composiçóes de águas ácidas da superfície de áreas vulcânicas ativas.

Custódio è al. (1971) (in Custódio \& Llamas 1976) estudaram a água intersticial das argilas do aquitard intermediário do delta do Llobregart; Custódio (1974) estudou a reatividade do maciço basáltico de Famara nas Ilhas Canárias; Pentcheva (1972) investigou a migração dos oligoelementos em águas termais; e Spears (1974) estudou as relaçōes entre cátions solúveis em água e paleossalinidade. Minami et al. (1973) realizou estudos experimentais sobre a reação entre rochas e águas termais do Japão.

Os processos de lixiviaçấo de urânio em diversos tipos de rochas magmáticas foram estudados por Szalay \& Sansoni (1973). Eles verificaram que a concentração de urấnio na água atinge, dentro de poucas horas, o valor de equilibrio para cada 
amostra e que o tamanho das partículas ou a superfície de contato não tem acentuada influência na solubilização.

Ellis \& Mahon (1964) realizaram testes de reatividade de rochas para diversas condições de temperatura e pressão, comparando os resultados com águas de sistemas hidrotermais naturais da Nova Zelândia.

Leonardos et al. (s.n.t.) realizaram experimentos com a finalidade de estudar a solubilização de nutrientes nas rochas e em fusōes silicatadas. Os resultados mostraram que a saturação dos nutrientes com água é da ordem de poucas horas (para o caso de vidros) e de cerca de um dia para o caso de rochas pulverizadas. Foi também observado que, como a velocidade da reação é rápida, a granulometria tem pouco efeito no nível dos nutrientes (intervalo de 20 a 300 meshes), sendo as concentrações encontradas da mesma ordem de grandeza das normalmente verificadas em água subterrânea (uma dezena de partes por milhão).

No Brasil, destacam-se os trabalhos de Portilho \& Leonardos (1976) e de Zamberlan \& Viana (1985). Os primeiros realizaram dezenas de medidas de $\mathrm{pH}$ de abrasão de rochas com o objetivo de avaliar sua solubilidade e seu potencial no método de rochagem para recuperação de solos. Os maiores valores de $\mathrm{Ph}$ foram encontrados em rochas cuja composição mineralógica contém nefelina ou olivina, entre as quais foram testados fonólitos e foiaítos de Poços de Caldas. Tal aumento de $\mathrm{pH}$ é explicado por reações de hidrólise dos minerais silicatados, sendo este processo muito rápido.

Zamberlan \& Viana (1985) realizaram experimentos em escala de campo com o objetivo de estudar a lixiviação de xisto betuminoso retortado na mina de São Mateus do Sul, no Paraná. Os resíduos sólidos - rejeito de mineração, xisto retortado, subsolo e solo - foram depositados em uma cava revestida e as amostras de água coletadas em drenos após chuvas fortes ocorridas na região.

\section{O AMBIENTE GEOQUÍMICO E A COMPOSIÇÃO DAS ÁGUAS SUBTERRÂNEAS Ambiente geoquímico O} maciço alcalino de Poços de Caldas, uma estrutura de forma ligeiramente circular com diâmetro em torno de $30 \mathrm{~km}$, é constituído de rochas da família dos nefelina-sienitos, representados por foiaítos, tinguaítos e fonólitos (Fig. 1). Subordinadamente, ocorrem brechas, aglomerados e tufos vulcânicos, além de restos de arenitos correlacionados à Formação Botucatu, da Bacia do Paraná (Bjornberg \& Landim 1966). A idade da intrusão alcalina é eocretácica e eocênica - de 60 a 80 milhões de anos, sendo que as últimas manifestaçōes vulcânicas datam de 55 milhōes de anos (Amaral 1967, Almeida 1967).

Os três tipos principais de rochas - foiaíto, tinguaíto e fonólito - mostram composição mineralógica e química muito semelhantes (Tab. 1), sendo diferentes apenas quanto à textura devido às condiçốes de resfriamento do magma original. Predominam os mineräis anortoclásio, sanidina, nefelina e aegirina. Os minerais acessórios mais comuns são analcita, titanita, magnetita, cancrinita, fluorita e zircão.

Não obstante a semelahnça dos tipos de rocha, quanto á sua mineralogia e à aparente uniformidade de composição química, uma mais complexa diferenciação e mineralizacão da área teve lugar devido à própria atividade vulcânica e aos processos hidrotermais e de intemperismo que se seguiram. As açôes hidrotermais desenvolveram diferentes tipos de míneralizações, assim descritas por Gorsky \& Gorsky (1970):

1. Mineralização tipo "A gostinho", em zonas de falhamento e brechação em tinguaítos alterados, apresentando-se em um típico net work de veios, filmes, acumulaçóes e impregnaçōes irregulares, com uma paragênese de pirita, fluorita e molibdenita uraníferas.

2. Mineralização em pequenos veios e acumulações de pirita, fluorita e molibdenita (com galena e cassiterita ocasionais) sem radiotividade ou pouco radioativas.

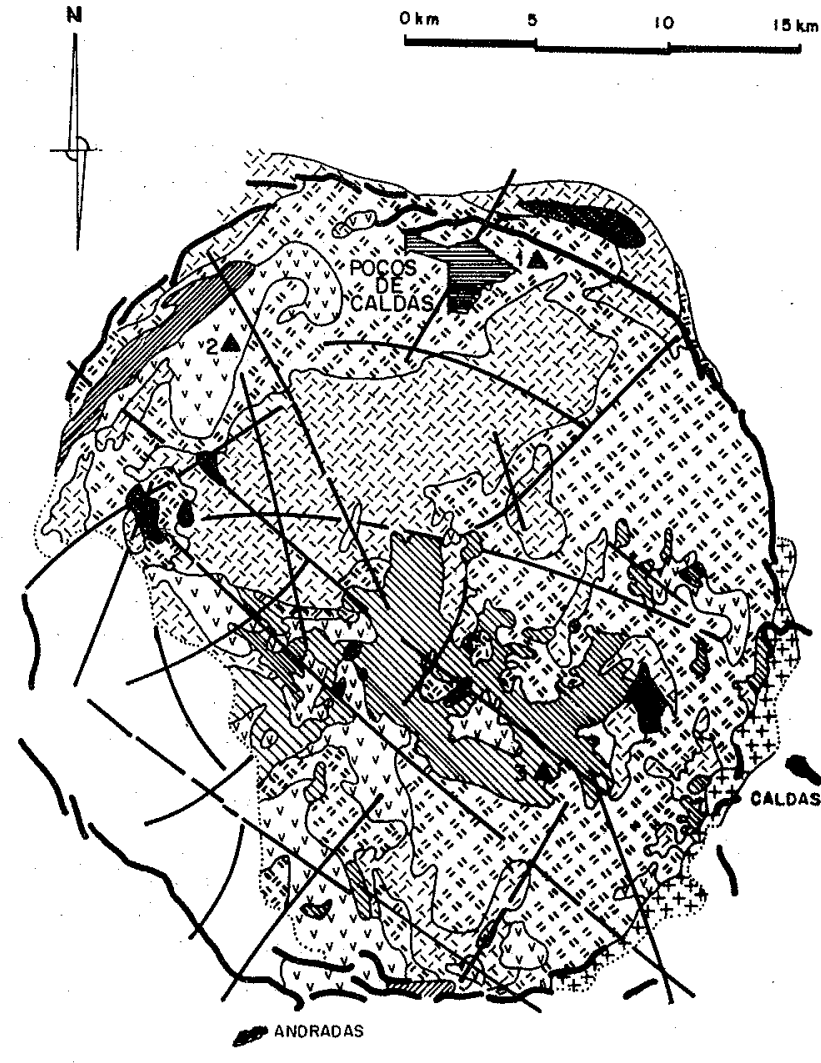

CONVENÇÕES

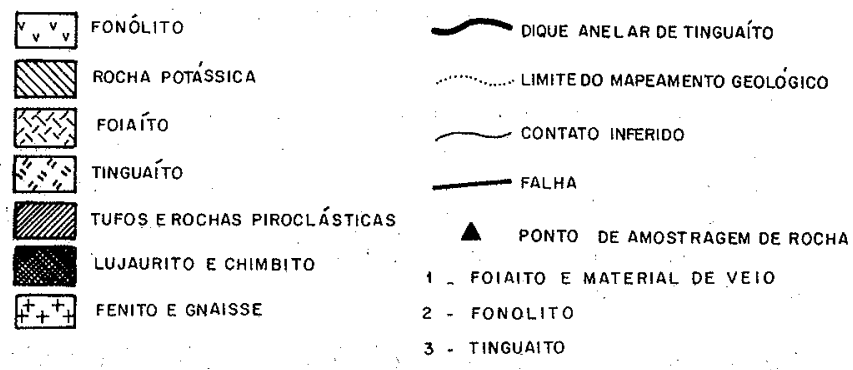

Figura 1 - Esboço geológico da chaminé alcalina de Poços de Caldas (Fonte: Gorsky \& Gorsky, 1970).

Figure 1 -Geological sketch of the Poços de Caldas alcaline complex. (according to Gorsky \& Gorsky, 1970)

3. Mineralização em rocha feldspática de textura cataclástica, miçrobrechosa, contendo veios e acumulações irregulares de diferentes agregados: $a$ ) ferro-rodocrosita, fluorita, pirita e siderita; $b$ ) soluções sólidas de $\mathrm{Mn}$ e $\mathrm{Fe}$; e $c$ ) pirita, pirrotita, fluorita, hematita, magnetita, secrita, clorita, traços de urânio e.tório.

4. Mineralização de caldasito, em veios - composta de óxido e silicato de zircônio - zircão e baddeleyta.

Os processos de meteorização e intemperismo contribuíram também para modificaçóes do ambiente geoquímico, resultando em uma variada gama de minerais secundários e supergênicoś. Esses processos incluem oxidação, especialmente dos minerais ferromagnesianos (acgirina e augita); cloritização, sericitização e caulinização dos feldspatos; e analcitização dos feldspatóides (nefelina), laterização e bauxitização. 
Tabela 1 - Análises químicas das rochas utilizadas nos experimentos (em \%)

Table 1 - Chemical analysis of rocks used in the experiments (in \%)

\begin{tabular}{|c|c|c|c|c|c|c|c|c|c|c|c|c|c|c|c|c|c|}
\hline № da Amostra/Rocha & $\mathrm{SiO}_{2}$ & $\mathrm{Al}_{2} \mathrm{O}_{3}$ & $\mathrm{Fe}_{2} \mathrm{O}_{3}$ & $\mathrm{Na}_{2} \mathrm{O}$ & $\mathbf{K}_{\mathbf{2}} \mathbf{O}$ & $\mathrm{CaO}$ & MgO & BaO & $\mathrm{NiO}$ & $\mathrm{TiO}_{2}$ & SrO & $\mathrm{ZnO}$ & $\mathrm{CuO}$ & Mno & $\mathbf{P}$ & $\mathbf{S}$ & $\mathbf{F}$ \\
\hline STQ-986 - Foiaíto (1) & 53,3 & 21,6 & 5,08 & 5,73 & 8,07 & 3,29 & 0,51 & 0,08 & $<0,01$ & 1,0 & $<0,01$ & 0,02 & $<0,01$ & 0,25 & 0,08 & 0,11 & 0,10 \\
\hline STQ-987 - Fonólito (2) & 3,0 & 20,2 & 5,25 & 6,94 & 8,49 & 2,32 & 0,27 & - & $<0,01$ & 0,62 & $<0,01$ & 0,02 & $<0,01$ & 0,25 & 0,05 & 0,06 & 0,10 \\
\hline $\begin{array}{c}\text { TQ-988 - Material de veio } \\
\text { alterado (1) }\end{array}$ & 51,2 & 15,7 & 8,25 & 1,48 & 11,02 & 3,26 & 0,51 & 0,03 & $<0,01$ & 1,35 & $<0,01$ & 0,12 & $<0,01$ & 0,97 & 0,06 & 0,06 & 0,10 \\
\hline STQ-989 - Tinguaíto (3) & 52,7 & $.22,4$ & 5,28 & 2,70 & 10,96 & 2,92 & 0,27 & - & $<0,01$ & 0,45 & $<0,01$ & 0,04 & $<0,01$ & 0,32 & 0,06 & 0,08 & 0,35 \\
\hline
\end{tabular}

Análise qualitativa por fluorescência de raios X

\begin{tabular}{lll}
\hline & $\mathrm{M}-\mathrm{Si}, \mathrm{Al}$ \\
Fonólito (2) & $\mathrm{Me}-\mathrm{K}, \mathrm{Na}, \mathrm{Fe}, \mathrm{Ca}$ \\
& $\mathrm{T}-\mathrm{Zr}, \mathrm{Sr}, \mathrm{Ti}, \mathrm{Mn}, \mathrm{Nb}, \mathrm{Rb}, \mathrm{Y}, \mathrm{Cl}, \mathrm{P}, \mathrm{Ga}, \mathrm{Cu}, \mathrm{Ni}, \mathrm{S}, \mathrm{Zn}$ \\
\hline & $\mathrm{M}-\mathrm{Si}, \mathrm{Al}$ \\
Fonólito (1) & $\mathrm{Me}=\mathrm{K}, \mathrm{Na}, \mathrm{Fe}, \mathrm{Ca}$ \\
& $\mathrm{T}-\mathrm{Zr}, \mathrm{Sr}, \mathrm{Ti}, \mathrm{Mn}, \mathrm{Nb}, \mathrm{Y}, \mathrm{O}, \mathrm{Cn}, \mathrm{Zn}, \mathrm{Ba}$
\end{tabular}

\footnotetext{
$\mathrm{M}$ - maiores constituintes (porcentagem $>20 \%$ )

$\mathrm{Me}=$ menores constituintes $\quad$ (porcentagem $<20 \%>1 \%$ )

$\mathrm{T}-$ traços $\quad$ (porcentagem $<1 \%$ )
}

PROCEDÊNCIAS: (1) Pedreira da Prefeitura Municipal de Poços de Caldas; (2) 2 km a oeste da Cia. Brasileira de Alumínio; (3) Jusante da represa da Nuclebrás. (Análises realizadas pelo Cetec).

Devem-se mencionar ainda, por sua ampla ocorrência na zona central da estrutura, as rochas alteradas que sofreram um enriquecimento em potássio até grandes profundidades (podendo chegar até a $16 \%$ de $\mathrm{K}_{2} \mathrm{O}$ ), designadas de "rochas potássicas", cuja origem é atribuída à meteorização e ao hidrotermalismo.

Composição dạ águas subterrâneas. Não há aqüíferos granulares superficiais de importância, ocorrendo na área os aqüíferos em meio fraturado. As águas subterrâneas ocorrem em nascentes difusas e certo número de fontes pontuais frias ou termais, estas últimas localizadas principalmente na depressão de Poços de Caldas (Fig. 2), o que permite identificar: 1. uma zona aqüífera rasa, de pequena profundidade; 2. uma zona aquíf́era intermediária; e 3. uma zona aqüífera de circulação profunda. Às duas primeiras zonas estão relacionadas a maior parte das fontes frias e as águas exploradas em poços tubulares (até $200 \mathrm{~m}$ de profundidade); à última zona estão associadas as fontes termais.

A origem das águas termais está relacionada a um extenso e profundo sistema de fraturas abertas, do qual foram identificadas em aerofotos pelo menos três direções principais: $\mathrm{N} 14^{\circ} \mathrm{E}, \mathrm{N} 50^{\circ} \mathrm{E}$ e $\mathrm{E}-\mathrm{W}$. As emergências das águas termais (fontes de Pedro Botelho e dos Macacos) localizaram-se exatamente no ponto de cruzamento ou de interconexão dessas três fraturas principais.

- A profundidade aparente de circulação, estimada com base na condutividade térmica das rochas (Araújo 1980), na geotemperatura da silica, na densidade de fluxo térmico e ainda na temperatura média anual da superfície (Hurter et al. 1983) é da ordem de 1.800 a $2.700 \mathrm{~m}$ (Cruz et al. 1987).

As águas subterrâneas apresentam características físico-químicas distintas, quer se trate de águas da zona mais superficial, da zona intermediária ou da zona de circulação profunda.
ÁGUAS DE NASCENTES E FONTES FRIAS São águas, em geral, com total de sólidos dissolvidos um pouco mais elevado que o das águas superficiais, com resíduo seco entre 27 e 100 ppm e um pouco mais ácidas ( $\mathrm{pH}$ de 5,4 e 6,9). Têm baixo conteúdo de $\mathrm{Cl}^{-}$e $\mathrm{SO}_{4}^{2-}$, com predomínio do íon bicarbonato, apresentando um pequeno incremento dos valores de dureza e quantidades aproximadamente equivalentes dos íons alcalinos $\mathrm{Na}^{+} \mathrm{e} \mathrm{K}+\mathrm{em}$ relação aos alcalinos-terrosos $\mathrm{Ca}^{2+}$ e $\mathrm{Mg}^{2+} . \mathrm{O}$ conteúdo em fluoreto é baixo, menor que $0,38 \mathrm{ppm}$. A tabela 2 mostra as características químicas gerais dessas fontes frias de circulação superficial.

Em relação aos constituintes menores, ocorrem na ordem de traços - 0,001 a 0,1 ppm - os elementos cobre, bário, manganês e zinco, enquanto não foram detectados (teores, se existentes, menores que os limites de detecção) 0 arsênio $(<0,02 \mathrm{ppm})$, selênio $(<0,006 \mathrm{ppm})$, cádmio $(<0,01 \mathrm{ppm})$, chumbo $(<0,07 \mathrm{ppm})$, cromo $(<0,02 \mathrm{ppm})$ e mercúrio $(<1,0$ ppm).

Em todas as águas das fontes pontuais citadas não foi detectada a presença de sulfetos $(<0,25 \mathrm{ppm})$, nem de urânio $(<0,001 \mathrm{ppm})$, tório $(<0,08 \mathrm{ppm})$ e rádio $226(<0,03$ $\mathrm{Bq} /$ /itro).

Essas fontes são caracterizadas pela presença de gás carbônico livre em concentraçōes que variam de 7 a 12 ppm.

À exceção das fontes de Santana 2 e XV de Novembro 2, todas as demais contêm teores signifícativos de radônio 222 (17 a $109 \mathrm{~Bq} /$ litro).

ÁGUAS DA ZONA INTERMEDIARIA Aqui referidas como as águas procedentes dos poços tubulares com profundidades até $150-200 \mathrm{~m}$ e temperaturas entre $21^{\circ} \mathrm{C}$ e $26^{\circ} \mathrm{C}$. Elas se diferenciam das águas da zona mais súperficial por apresentar um incremento de sólidos totais dissolvidos (resíduo seco de 55 a $186 \mathrm{ppm}$ ); uma elevação gradativa de $\mathrm{pH}$, predominando águas neutras e levemente alcalinas ( $\mathrm{pH}$ 


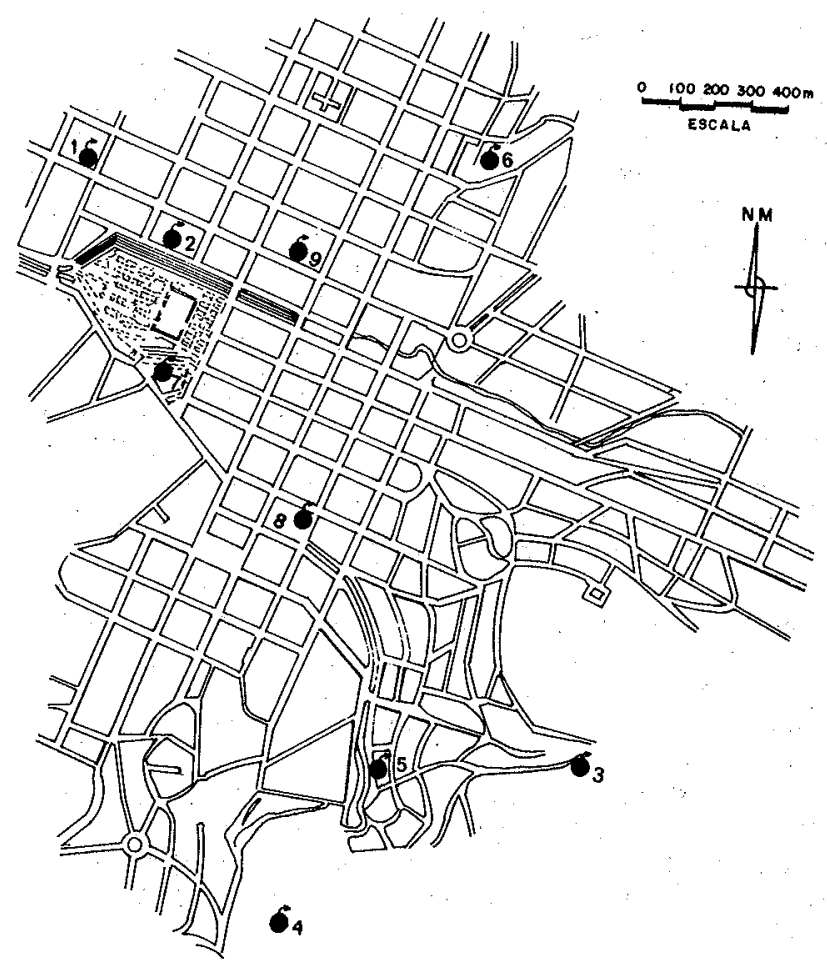

LEGENDA

$$
1 \text { - FRAYHA }
$$$$
2\left\{\begin{array}{l}
\text { SANTANA } 1 \\
\text { SANTANA } 2
\end{array}\right.
$$$$
3 \text { - MONJOLINHO }
$$

XXV DE NOVEMBRO

4 XV DE NOVEMBRO 2

QUISISANA FERRUGINOSA

LQUISISANA SULFOROSA

5 - SANTO ANTÔNIO
6. SÃO JOÁO

7 - PEDRO BOTELHO

8 - DOS MACACOS

9. SINHAZINHA

FONTE

Figura 2 - Mapa de localização dos pontos de água - 1 . Frayha; 2. Santana 1, Santana 2; 3. Monjolinho; etc...

Figure. 2 - Location map of the water flowing points

variando de 6,2 a 8,4 ); e aumento das concentraçóes de bicarbonato e sódio. Os teores de cloretos mostram apenas uma pequena elevação enquanto as concentrações de $\mathrm{Ca}^{2+}$, $\mathrm{Mg}^{2+}$ e $\mathrm{SO}_{4}^{2-}$ não mostram variações significativas.

As concentrações de fluoretos variam de 0,27 a $6,8 \mathrm{ppm}$, ocorrendo um máximo de $17,5 \mathrm{ppm}$.

As concentraçōes de ferro total e manganês são inferiores a 0,5 e $0,05 \mathrm{ppm}$, respectivamente, tendo-se determinado valores de $5 \mathrm{ppm}$ de $\mathrm{Fe}$ e 0,11 de $\mathrm{Mn}$ apenas no poço PCF-003, Vila Togni; o zinco varia de 0,02 a $0,46 \mathrm{ppm}$, não tendo sido detectados alumínio $(<0,5 \mathrm{ppm})$, bário $(<0,2$ ppm), cobre $(<0,05 \mathrm{ppm})$ e arsênio $(<0,001: \mathrm{ppm})$. A composição dessas águas é mostrada na tabela 2 .

ÁGUAS TERMAIS As águas termais são as provenientes das fontes Pedro Botelho e dos Macacos, cujas características quanto aos maiores constituintes constam da tabela 3.

São águas hipertermais, alcalinas, bicarbonatadas sódicas e sulfurosas. Diferenciam-se em relação às águas subterrâneas, já descritas, por apresentar temperaturas de $40^{\circ} \mathrm{C}$ a $44^{\circ} \mathrm{C}$; um aumento acentuado do total de sólidos dissolvidos (resíduo

Tabela 2 - Composição das fontes de circulação superficial (A) e das águas subterrâneas da zona intermediária (B) (em ppm)

Table 2 - Composition of the shallow circulation water (A) and groundwater of the intermediate zone (B) (in ppm)

\begin{tabular}{|c|c|c|c|c|c|c|}
\hline \multirow[t]{2}{*}{ Determinaçöes } & \multicolumn{2}{|c|}{$\begin{array}{l}\text { Valores } \\
\text { mínimos }\end{array}$} & \multicolumn{2}{|c|}{$\begin{array}{l}\text { Valores } \\
\text { máximos }\end{array}$} & \multicolumn{2}{|c|}{$\begin{array}{c}\text { Composição } \\
\text { média }\end{array}$} \\
\hline & $\overline{\mathbf{A}}$ & B & $\mathbf{A}$ & B & $\mathbf{A}$ & $\mathbf{B}$ \\
\hline Temperatura $\left({ }^{\circ} \mathrm{C}\right)$ & 18,4 & 21 & 24,5 & 26 & 21,5 & 22,7 \\
\hline $\mathrm{pH}$ & 5,4 & 6,2 & 6,9 & 8,4 & - & - \\
\hline $\begin{array}{l}\text { Condutividade em } \\
\mu \mathrm{mho} / \mathrm{cm}\end{array}$ & 10,0 & 44,0 & 105,5 & 243,0 & 49,8 & 110,40 \\
\hline Residuo seco & 27,00 & 55,00 & 100,00 & 186,50 & 56,60 & 127,10 \\
\hline $\begin{array}{l}\text { Dureza total em } \\
\text { ppm } \mathrm{CaCO}_{3}\end{array}$ & - & 8,00 & - & 39,50 & 13,33 & 18,50 \\
\hline $\mathrm{Ca}^{2+}$ & 0,40 & 1,60 & 10,80 & 15,04 & 6,23 & 6,07 \\
\hline $\mathrm{Mg}^{2+}$ & 0,20 & 0,01 & 0,92 & 2,54 & 0,60 & 0,98 \\
\hline $\mathrm{Na}^{+}$ & 0,80 & 6,50 & 7,50 & 48,75 & 4,30 & 32,30 \\
\hline $\mathrm{K}^{+}$ & 0,80 & 1,07 & 6,50 & 4,0 & 4,15 & ì,95 \\
\hline $\mathrm{HCO}_{\overline{3}}^{-}$ & 6,10 & 20,74 & 34,70 & 138,30 & 14,47 & 62,66 \\
\hline $\mathrm{CO}_{3}^{2-}$ & - & - & - & 12,50 & - & 12,00 \\
\hline $\mathrm{Cl}^{-}$ & 0,40 & 0,50 & 9,00 & 12,00 & 3,17 & 4,82 \\
\hline $\mathrm{SO}_{4}^{2-}$ & 0,50 & 1,00 & 1,20 & 2,70 & 0,93 & $13 ; 67$ \\
\hline Fe total & - & 0,08 & - & 5,00 & - & 1,02 \\
\hline $\mathrm{F}^{-}$ & 0,08 & 0,27 & 0,38 & 17,50 & 0,18 & 5,84 \\
\hline
\end{tabular}

seco em torno de $580 \mathrm{ppm}$ ) e pH entre 9,6 e 9,8 (Tab. 3), acompanhado de maiores concentraçōes de carbonatos, sódio, sulfetos e fluoretos.

Os teores de sulfetos variam de 1,6 a 2,7 ppm, a maior parte presente na forma de íon $\mathrm{SH}^{-}$dissolvido. Apresentam ainda uma quantidade de silica $\left(\mathrm{SiO}_{2}^{2-}\right)$ igual a $29,4 \mathrm{ppm}$ e concentrações de fluoretos de $24 \mathrm{ppm}$.

Entre os elementos menores destacam-se o ferro $(0,1 \mathrm{ppm})$ e o alumínio $(0,10$ e $0,11 \mathrm{ppm})$, não tendo sido detectados os metais arsênio, zinco, cádmio e cobre.

Contêm, ainda, radônio 222 em concentrações de 3,7 e 2,7 unidades Mache, sendo que rádio 226 não foi detectado (limite de detecção do método $=0,03 \mathrm{~Bq} /$ litro).

Não foram feitas determinações sobre as concentraçōes e a composição de gases nas emergências. Pelas análises existentes e observações in loco, ocorre pequena proporção de gases dissolvidos. Além do radônio, há indicação da presença de nitrogênio na concentração de $15,0 \mathrm{ml} \mathrm{a.} 0^{\circ} \mathrm{C}$ e $760 \mathrm{~mm}$ de pressão atmosférica, conforme determinado pelo Instituto Oswaldo Cruz. Gás sulfúrico, se existente, deve ocorrer em pequena quantidade.

Ocorrem ainda duas emergências de águas subterrâneas com características semelhantes às anteriormente descritas, à exceção de sua termalidade: são as fontes de Sinhazinha e Quisisana Sulfurosa.

A fonte Sinhazinha classifica-se como fonte fria 
Tabela 3 - Composição das águas da zona de circulaçāo profunda (em ppm)

Table 3 - Composition of deep circultion water (in ppm)

\begin{tabular}{|c|c|c|c|c|}
\hline Determinaçōes & $\begin{array}{c}\text { Fonte } \\
\text { Pedro } \\
\text { Botelho }_{(1)}\end{array}$ & $\begin{array}{c}\text { Fonte } \\
\text { dos } \\
\operatorname{Macacos}_{(1)}\end{array}$ & $\begin{array}{c}\text { Fonte } \\
\text { Quisisana } \\
\text { Sulfurosa } \\
\end{array}$ & $\begin{array}{l}\text { Fonte } \\
\text { Sinha- } \\
\text { zinha }_{(3)}\end{array}$ \\
\hline Temperatura $\left({ }^{\circ} \mathrm{C}\right)$ & 44,0 & 40,0 & 28,8 & 22,3 \\
\hline $\mathrm{pH}$ & 9,6 & 9,8 & 9,6 & 10,0 \\
\hline $\begin{array}{l}\text { Condutividade em } \\
\mu \mathrm{mho} / \mathrm{cm}\end{array}$ & 985,0 & 1010,0 & 505,0 & 830,0 \\
\hline Resíduo seco & 580,5 & 579,3 & 398,5 . & 574,2 \\
\hline $\begin{array}{l}\text { Dureza em } \\
\text { ppm CaCO }\end{array}$ & 5,00 & 5,75 & 2,20 & 10,00 \\
\hline $\mathrm{Ca}^{2+}$ & 1,14 & 1,25 & 2,65 & 4,17 \\
\hline $\mathrm{Mg}^{2+}$ & 0,46 & 0,11 & 0,50 & 0,55 \\
\hline $\mathrm{Na}^{+}$ & 210,72 & 214,87 & 138,00 & 217,50 \\
\hline $\mathrm{K}^{+}$ & 6,80 & 7,20 & 4,95 & 5,97 \\
\hline $\mathrm{HCO}_{3}^{-}$ & 147,72 & 170,90 & 156,20 & 144,10 \\
\hline $\mathrm{CO}_{3}^{2-}$ & 146,22 & 129,60 & 66,00 & 148,20 \\
\hline $\mathrm{Cl}^{-}$ & 5,65 & 3,96 & 2,58 & 4,29 \\
\hline $\mathrm{SO}_{4}^{2-}$ & 56,25 & 62,50 & 43,14 & 77,00 \\
\hline Fe total & 0,10 & - & 0,07 & - \\
\hline $\mathrm{F}^{-}$ & 24,10 & 24,85 & 16,99 & 33,10 \\
\hline $\mathrm{Ba}^{2+}$ & $<0,01$ & 0,043 & 0,043 & 0,061 \\
\hline As (total) & $<0,02$ & $<0,02$ & $<0,02$ & $<0,02$ \\
\hline $\mathrm{Zn}^{2+}$ & $<0,06$ & $<0,06$ & 0,023 & 0,028 \\
\hline $\mathrm{Cd}^{2+}$ & $<0,01$ & $<0,01$ & $<0,01$ & $<0,01$ \\
\hline $\mathrm{Cu}^{2+}$ & $<0,01$ & $<0,01$ & 0,044 & 0,015 \\
\hline $\mathrm{Al}^{3+}$ & 0,01 & 0,11 & $<0,05$ & - \\
\hline
\end{tabular}

(1) Água hipertermal

(2) Água hipotermal

(3) Água fria

(temperatura de $22,3^{\circ} \mathrm{C}$ ) e a Quisisana Sulfurosa é hipotermal (temperatura $=28,8^{\circ} \mathrm{C}$ ).

Em termos de sólidos dissolvidos, a fonte Sinhazinha é semelhante às fontes termais ( $\mathrm{SD}=574,2 \mathrm{ppm}$ ) enquanto a Quisisana Sulfurosa é menos mineralizada $(\mathrm{SD}=398,5 \mathrm{ppm})$. Em relação à alcalinidade, conteúdo em sódio, $\mathrm{HCO}_{3}^{-}$e fluoretos assemelham-se às fontes termais. As concentrações de sulfetos são de $2,0 \mathrm{ppm}$ na fonte Sinhazinha e de $0,5 \mathrm{ppm}$ na Quisisana Sulfurosa, sendo mais elevadas as concentrações de radônio (14,9 e 3,9 maches, respectivamente).

Evolução química das águas A evolução química das águas subterrâneas com a profundidade pode ser descrita, em linhas gerais, como se segue.

A partir do momento que as águas se infiltram, há dissolução de $\mathrm{CO}_{2}$ e de ácidos úmicos provenientes da matéria orgânica do solo, aumentando sua acidez e conseqüente capacidade de dissolução.

As águas subterrâneas da zona superficial, incluindo as nascentes e fontes frias, têm composição influenciada principalmente por este aumento de $\mathrm{CO}_{2}$. Têm baixo conteúdo de sólidos dissolvidos e são mais ácidas que as águas superficiais, o que permite $o$ ataque às argilas $e$ rochas alteradas, com incorporação de maior quantidade de $\mathrm{Ca}^{2+}$,

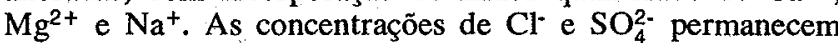
praticamente inalteradas em relação às águas superficiais, aumentando apenas o bicarbonato. São águas de ambiente oxidante, com ausência de sulfetos e caracterizadas por uma maior concentração de $\mathrm{Rn}^{222}$ e $\mathrm{CO}_{2}$ livre.

À medida que aumenta a profundidade, ocorre uma lenta $e$ progressiva elevação do $\mathrm{pH}$, enriquecimento em $\mathrm{HCO}_{3}^{-}, \mathrm{Na}^{+}$, $\mathrm{SO}_{4}^{2-}$ e silica, acompanhado de uma alta concentracão de fluoreto. As águas tendem para um ambiente redutor, apresèntando aumento de sulfetos e decréscimo da radioatividade.

Estas modificações que se verificam com o percurso subterrâneo e com o tempo de contato água-rocha são máximas nas fontes termais de circulação profunda, mas se observa esta tendência desde a zona intermediária (até 150-200 m).

OS EXPERIMENTOS Quatro tipos de materiais dos mais representativos da área foram coletados - foiaíto, fonólito, tinguaíto brechado e material de preenchimento de veio. Em seguida, foram triturados e imersos em água sob diversas condições de temperatura e pH. As soluções resultantes para diferentes tempos (de oito a 1.176 horas) foram analisadas a fim de verificar a proporção na qual os vários elementos foram liberados das rochas; quando o equilíbrio entre água e sólido foi alcançado para cada elemento; e se ocorreu contínua ou completa lixiviação da rocha. A composição das soluçōes experimentais foi, posteriormente, comparada com as das águas subterrâneas, em especial com as águas termais.

As amostras dos materiais foram procedentes das seguintes localidades (Fig. 1):

- Foiaíto: pedreira da Prefeitura Municipal de Poços de Caldas, na Serra de São Domingos.

- Fonólito: local $2 \mathrm{Km}$ a oeste da Companhia Brasileira de Alumínio.

- Tinguaíto brechado: local a jusante da represa da Nuclebrás, a sul da área estudada, no vale do Ribeirâo das Antas.

- Material de preenchimento de veio: pedreira da Prefeitura Municipal de Poços de Caldas, na Serra de São Domingos.

A preparação das amostras constou de moagem e peneiramento a seco, em peneira de 280 meshes, correspondendo a uma granulometria de areia fina a média. Uma fração do material foi separada para análise química qualitativa por difração de raios $X$ e outra fração do mateıial homogeneizado foi submetida a análise química por via úmida e absorção atômica. $\mathrm{O}$ restante do material foi dividido em frações de $500 \mathrm{~g}$ para os testes de imersão.

Cada tipo de material foi imerso em 1 litro de água nas seguintes condiçōes:

- com água destilada a temperatura ambiente;

- com água destilada a $80^{\circ} \mathrm{C}$ (temperatura estimada do reservatório das fontes termais em profundidade); e

- com água carbonatada alcalina ( $\mathrm{pH}=9$ ) a $40^{\circ} \mathrm{C}$ (temperatura na emergência das fontes termais). (Os experimentos para esta condição estão ainda em execução).

A temperatura foi controlada em estufa, procedendo-se à agitação da água duas vezes por dia. As amostras da solução 
foram retiradas para análise nos seguintes tempos: oito horas, um, três, sete e 21 dias. Nas amostras de tinguaíto brechado e do material de preenchimento de veio, a última amostra foi retirada após 49 dias em vez de 21 dias. Após filtragem, as amostras foram analisadas, determinando-se os seguintes parâmetros: $\mathrm{pH}$, condutividade elétrica, alcalinidade total, de bicarbonato e carbonato, cloretos, sulfatos, fluoretos, sódio, potássio, cálcio, magnésio, silica, alumínio, ferro e manganês.

Os seguintes métodos de análises foram utilizados: alcalinidade - titulométrico; cloretos - colorimétrico; sulfato turbidimétrico; fluoreto - eletrodo seletivo; constituintes metálicos - absorção atômica; silício - gravimétrico.

APRESENTAÇÃO DOS RESULTADOS Petrografia e composição das rochas Os quatro tipos de rochas selecionados são dos mais representativos do complexo alcalino de Poços de Caldas.

O foiaíto é uma rocha de cor cinza-claro, textura fanerítica, granulação grossa. Os minerais predominantes são feldspatos alcalinos - sanidina e anortoclásio - e feldspatóides - nefelina e alguma leucita com piroxênios do tipo aegirina-augita. Minerais acessórios: biotita, apatita, magnetita, zircão, titanita, pirita e fluorita.

O fonólito é de cor cinza-escuro, duro, compacto, não-poroso, de granulação muito fina, textura holocristalina afanítica, constituído de feldspatos (sanidina, ortoclásio e microclina) e piroxênio (aegirina).

O tinguaíto brechado é de cor cinza passando a esverdeada, granulação fina e de composicão mineralógica semelhante à do foiaíto.

O material de preenchimento de veio é heterogêneo, constituído de um agregado fino, alterado, com manchas de óxido de ferro.

Os resultados das análises químicas das rochas utilizadas nos ensaios constam da tabela 1 .

Composição das soluções Nas tabelas 4 e 5 , constam os resultados das análises das soluções resultantes das interações água-rocha para as diferentes condições dos ensaios e diferentes tempos de reação. Nas figuras de 3 a 10 mostra-se a evolução das concentraçōes com o tempo.

ANÁlISE DOS RESULTADOS Nos experimentos de interação água-rocha, as condições que ocorrem nos sistemas hídricos naturais não podem ser totalmente reproduzidas ou simuladas em laboratório. Condiçōes de temperatura, pressão e $\mathrm{pH}$ podem ser reproduzidas com certa facilidade; a superfície de contato água-rocha e o tempo de contato só em parte podem ser simulados, fragmentando-se a rocha em variadas granulometrias ou forçando-se o intercâmbio, mantendo certa agitação na água durante o ensaio. As maiores dificuldades prendem-se ao fato de não serem conhecidos, nos sistemas naturais, a superfície de contato água-rocha ou a razão rocha-água que está relacionada ao volume de água circulante, velocidade de circulação, características do meio aqüífero e tempo de residência. Nessas condições, os resultados dos experimentos fornecem apenas uma idéia sobre os constituintes que podem ser removidos mais facilmente em solução, velocidade ou tempo de reação, equilíbrios químicos, sendo de natureza mais qualitativa do que quantitativa.

Os resultados expressos na tabela 6 mostram que, entre os quatro tipos de materiais testados, o foiaíto foi a rocha mais reativa, seguida do tinguaíto e em menor proporção o fonólito e o material alterado de preenchimento de veio - a temperatura exercendo, em todos os casos, uma influência acentuada na mineralização das soluções de reação. No conjunto, a velocidade de reação é rápida. Do total de constituintes extraídos das rochas ao final de 21 e 49 dias, cerca de $31,5 \%$ a $58 \%$ foram liberados nas primeiras oito horas de reação. Para a maioria dos constituintes, não foi

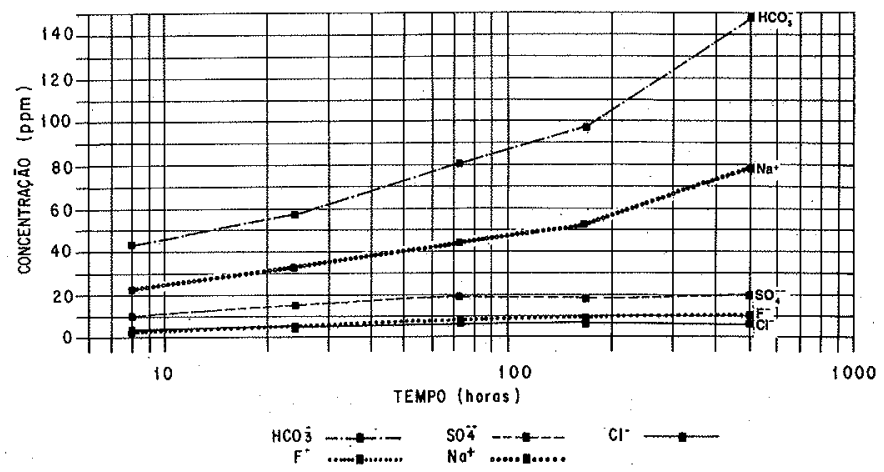

Figura 3 - Evolução das concentrações com o tempo de reação para as soluções em foiaíto à temperatura ambiente Figure 3 - Evolution of the concentrations with reaction time in foyaite under environmental temperature

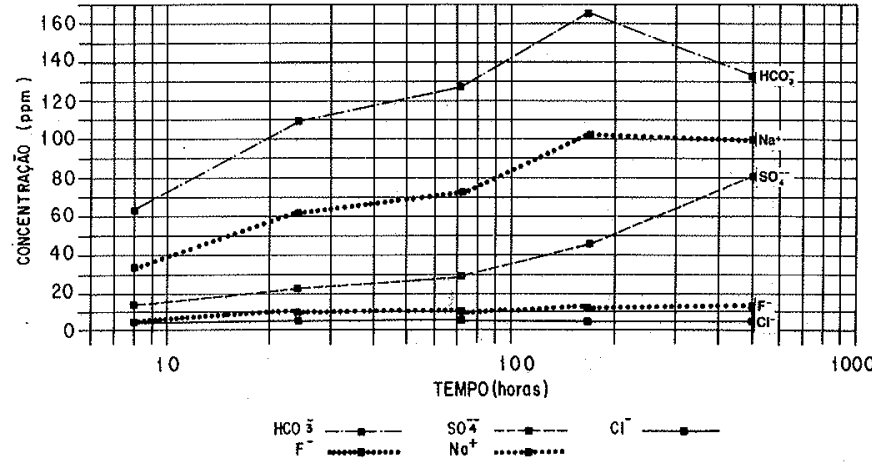

Figura 4 - Evolução das concentraçōes corn o tempo de reação para as soluções em foiaíto a $80^{\circ} \mathrm{C}$

Figure 4-Evolution of the concentrations with reaction time for solutions in foyaite under $80^{\circ} \mathrm{C}$

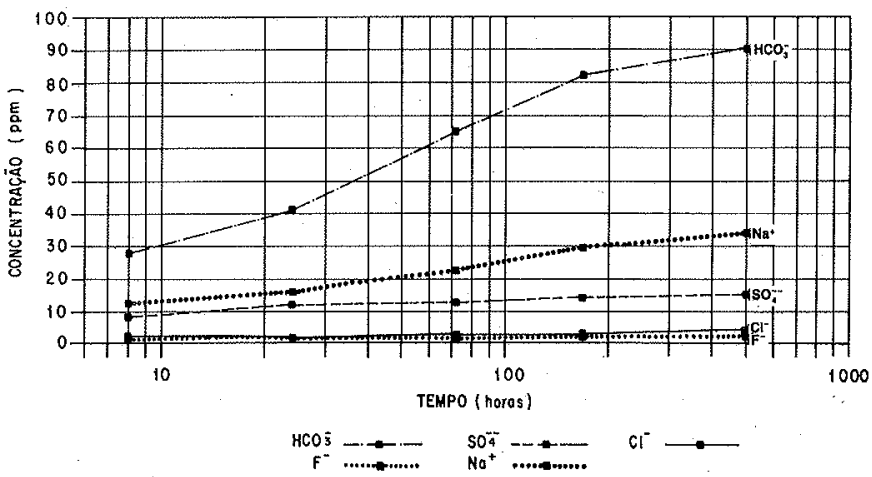

Figura 5 - Evolução das concentrações com o tempo de reação para as soluções em fonólito à temperatura ambiente Figure 5-Evolution of the concentrations with reaction time for solutions in tinguaite under environmental temperature

atingido o estado de equilíbrio ou o produto de solubilidade, indicando que maiores concentraçöes seriam atingidas para maior tempo de reação. $\mathrm{O} \mathrm{pH}$ das soluçōes mostrou progressiva elevação com 0 tempo, independente da 
Tabela 4 - Concentração dos constituintes das soluções de reação (em ppm)

Table 4-Concentration of the reaction solutions components (in ppm)

Tipo de rocha: Foiaíto

\begin{tabular}{|c|c|c|c|c|c|c|c|c|c|c|c|c|c|c|c|c|}
\hline $\begin{array}{c}\text { Tempera: } \\
\text { tura }{ }^{\circ} \mathrm{C}\end{array}$ & $\begin{array}{c}\text { Tempo de } \\
\text { reação } \\
\text { (Horas) }\end{array}$ & $\mathrm{pH}$ & $\begin{array}{c}\text { Cond. } \\
\mu \mathrm{mho} / \mathrm{cm}\end{array}$ & $\mathrm{HCO}_{3}^{-}$ & $\mathrm{CO}_{3}^{2+}$ & $\mathrm{SO}_{4}^{2-}$ & $\mathrm{Cl}^{-}$ & $\mathbf{F}^{-}$ & $\mathrm{Na}^{+}$ & $\mathbf{K}^{+}$ & $\mathrm{Ca}^{2+}$ & $\mathbf{M g}^{2+}$ & $S i^{4+}$ & $\mathrm{Al}^{3+}$ & $\begin{array}{c}\text { Mn } \\
\text { total }\end{array}$ & $\begin{array}{c}\mathrm{Fe} \\
\text { total }\end{array}$ \\
\hline Ambiente & $\begin{array}{r}8 \\
24 \\
72 \\
168 \\
504 \\
1176\end{array}$ & $\begin{array}{c}7,4 \\
7,99 \\
8,11 \\
8,25 \\
8,53 \\
-\end{array}$ & $\begin{array}{c}172 \\
162 \\
220 \\
254 \\
350 \\
-\end{array}$ & $\begin{array}{r}44,0 \\
57,4 \\
80,5 \\
97,3 \\
147,7 \\
-\end{array}$ & $\begin{array}{c}- \\
- \\
- \\
0,48 \\
3,24 \\
-\end{array}$ & $\begin{array}{c}10,6 \\
14,8 \\
19.1 \\
18.1 \\
19,9 \\
-\end{array}$ & $\begin{array}{c}3,91 \\
5,62 \\
5,70 \\
6,86 \\
6,28 \\
-\end{array}$ & $\begin{array}{r}2,78 \\
4,58 \\
7,93 \\
9,26 \\
10,73 \\
-\end{array}$ & $\begin{array}{l}22,50 \\
33,0 \\
44,0 \\
53,00 \\
78,00 \\
-\end{array}$ & $\begin{array}{l}2,05 \\
2,64 \\
3,26 \\
3,54 \\
4,79 \\
-\end{array}$ & $\begin{array}{c}2,02 \\
2,49 \\
2,30 \\
2,83 \\
4,54 \\
-\end{array}$ & $\begin{array}{c}0,08 \\
0,11 \\
0,11 \\
0,12 \\
0,27 \\
-\end{array}$ & $\begin{array}{r}<2,0 \\
5,0 \\
2,0 \\
2,5 \\
3,0 \\
-\end{array}$ & $\begin{array}{c}\overline{7,73} \\
- \\
0,68 \\
0,68 \\
-\end{array}$ & $\begin{array}{c}<0,05 \\
<0,05 \\
<0,05 \\
<0,05 \\
<0,05 \\
-\end{array}$ & $\begin{array}{c}<0,05 \\
<0,21 \\
<0,05 \\
<0,05 \\
<0,05 \\
-\end{array}$ \\
\hline $80^{\circ} \mathrm{C}$ & $\begin{array}{r}8 \\
24 \\
72 \\
168 \\
504 \\
1176\end{array}$ & $\begin{array}{c}7,56 \\
8,06 \\
8,04 \\
7,91 \\
8,24 \\
-\end{array}$ & $\begin{array}{c}156 \\
276 \\
330 \\
440 \\
452 \\
-\end{array}$ & $\begin{array}{r}63,2 \\
109,0 \\
127,6 \\
165,9 \\
133,3 \\
-\end{array}$ & $\begin{array}{l}- \\
- \\
- \\
-\end{array}$ & $\begin{array}{c}14,0 \\
22,6 \\
28,9 \\
45,8 \\
81,0 \\
-\end{array}$ & $\begin{array}{c}4,39 \\
5,61 \\
5,95 \\
5,62 \\
5,10 \\
-\end{array}$ & $\begin{array}{r}5,06 \\
9,66 \\
11,14 \\
12,56 \\
13,42 \\
-\end{array}$ & $\begin{array}{r}34,25 \\
61,00 \\
72,00 \\
102,25 \\
99,50 \\
-\end{array}$ & $\begin{array}{r}3,49 \\
7,79 \\
8,69 \\
10,89 \\
10,64 \\
-\end{array}$ & $\begin{array}{c}2,13 \\
1,39 \\
1,45 \\
0,65 \\
1,32 \\
-\end{array}$ & $\begin{array}{c}<0,05 \\
<0,05 \\
<0,05 \\
<0,05 \\
<0,05 \\
-\end{array}$ & $\begin{array}{r}3,50 \\
7,0 \\
11,0 \\
8,0 \\
12,0 \\
-\end{array}$ & $\begin{array}{c}1,14 \\
1,82 \\
7,73 \\
- \\
2,05 \\
-\end{array}$ & $\begin{array}{c}<0,05 \\
<0,05 \\
<0,05 \\
<0,05 \\
<0,05 \\
-\end{array}$ & $\begin{array}{r}<0,05 \\
0,05 \\
0,12 \\
<0,05 \\
0,26 \\
-\end{array}$ \\
\hline
\end{tabular}

Tipo de rocha: Fonólito

\begin{tabular}{l|r|r|c|c|c|c|c|c|c|c|c|c|c|c|c|c}
\hline Ambiente & 8 & 7,53 & 66 & 27,8 & - & 8,2 & 2,07 & 1,13 & 12,00 & 2,36 & 1,62 & 0,03 & $<2,0$ & - & $<0,05$ & $<0,05$ \\
& 24 & 7,82 & 102 & 40,5 & - & 12,1 & 1,92 & 1,33 & 15,50 & 2,96 & 3,52 & 0,06 & 2,0 & - & $<0,05$ & $<0,05$ \\
& 72 & 7,60 & 142 & 64,9 & - & 12,5 & 2,73 & 1,42 & 22,00 & 4,15 & 6,24 & 0,10 & 3,0 & - & $<0,14$ & $<0,05$ \\
& 168 & 8,07 & 178 & 82,2 & - & 14,0 & 3,00 & 2,04 & 29,00 & 5,80 & 8,34 & 0,10 & 3,50 & - & $<0,16$ & $<0,05$ \\
& 504 & 8,25 & 194 & 90,4 & 1,08 & 14,8 & 3,98 & 2,35 & 34,00 & 5,80 & 5,99 & 0,09 & 3,0 & - & $<0,15$ & $<0,05$ \\
& 1176 & - & - & - & - & - & - & - & - & - & - & - & - & - & - & - \\
\hline $80^{\circ} \mathrm{C}$ & 8 & 7,74 & 166 & 44,1 & - & 11,3 & 2,96 & 1,77 & 20,50 & 5,20 & 2,12 & $<0,05$ & 3,50 & - & $<0,05$ & $<0,05$ \\
& 24 & 8,05 & 192 & 80,3 & - & 16,8 & 6,8 & 2,80 & 36,25 & 8,90 & 2,33 & $<0,05$ & 7,0 & - & $<0,05$ & $<0,05$ \\
& 72 & 7,72 & 260 & 101,9 & - & 23,0 & 8,92 & 4,49 & 54,50 & 12,00 & 1,10 & $<0,05$ & 8,0 & 1,13 & $<0,05$ & $<0,05$ \\
& 168 & 8,14 & 275 & 100,6 & - & 28,1 & 9,86 & 5,94 & 59,75 & 11,75 & 0,64 & $<0,05$ & 6,5 & 0,68 & $<0,05$ & $<0,05$ \\
& 504 & 7,83 & 300 & 63,4 & - & 56,2 & 10,42 & 7,38 & 58,00 & 10,50 & 0,51 & $<0,05$ & 4,0 & 1,36 & $<0,05$ & 0,05 \\
& 1176 & - & - & - & - & - & - & - & - & - & - & - & - & - & - & - \\
\hline
\end{tabular}

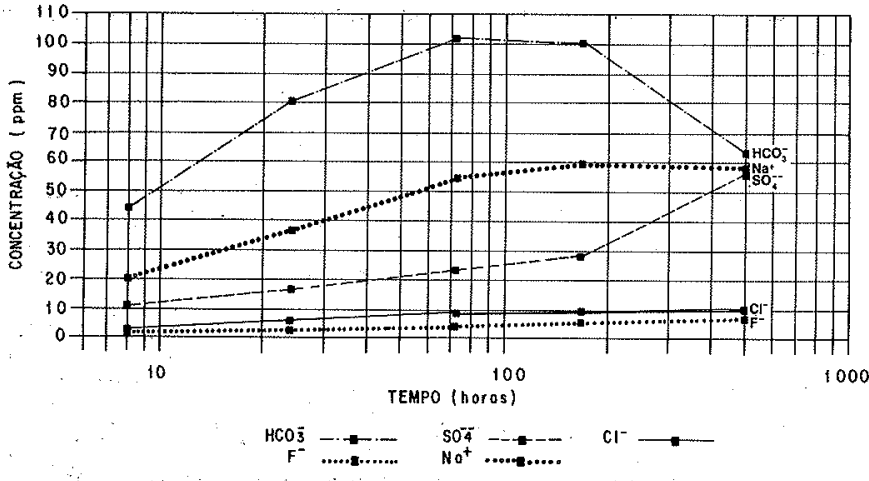

Figura 6 - Evolução das concentrações com o tempo de reação para ạs soluções em fonólito a $80^{\circ} \mathrm{C}$

Figure 6 - Evolution of the concentrations with reaction time for solutions in phonolite under environmental temperature

temperatura da água, atingindo um valor máximo de 8,5 na solução de reação com o foiaíto à temperatura ambiente.

Constituintes maiores das rochas Dos elementos contidos em excesso na rocha - silício, alumínio e ferro -, apenas o silício tem maior mobilidade. A solubilidade do quartzo é baixa enquanto a sílica amorfa é mais solúvel, podendo chegar a $160 \mathrm{ppm}$ a $25^{\circ} \mathrm{C}$, em água pura, e a 400 ppm a $100^{\circ} \mathrm{C}$ : $O$ alumínio, em geral, $e$ fortemente retido na

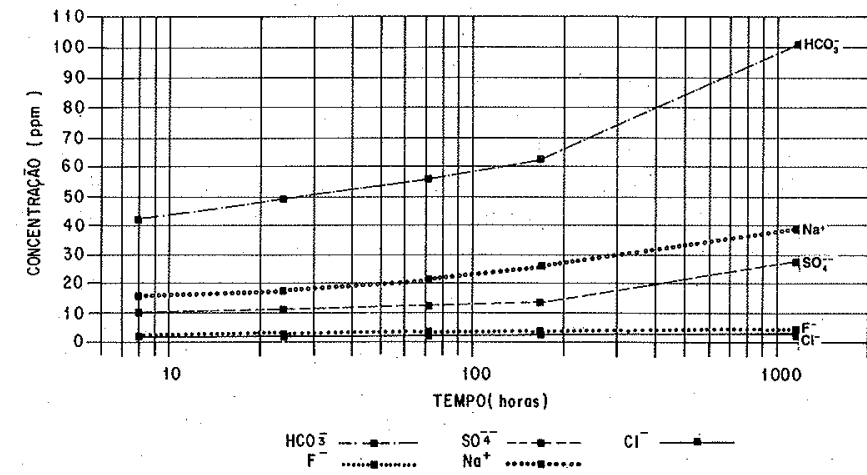

Figura 7 - Evolução das concentrações com o tempo de reação para as soluções em tinguaíto à temperatura ambiente Figure 7 - Evolution of the concentrations with reaction time for solutions in phonolite under environmental temperature

estrutura cristalina dos silicatos e nos produtos de alteração. Juntamente com o ferro, mostra maior solubilidade em águas ácidas, mas comparecem em pequenas concentraçōes em águas básicas.

As concentrações de $\mathrm{Fe}$ nas soluções de reação, em geral, não excederam $0,05 \mathrm{ppm}$, sendo não-detectáveis, como seria de esperar, em condições de $\mathrm{pH}$ em torno de 8 . O alumínio não foi detectado nas soluções do material alterado de veio e 
Tabela 5 - Concentração dos constituintes das soluções de reação (em ppm)

Table 5-Concentration of the reaction solutions components (in ppm)

Tipo de rocha: Tinguaíto Brechado

\begin{tabular}{|c|c|c|c|c|c|c|c|c|c|c|c|c|c|c|c|c|}
\hline $\begin{array}{c}\text { Tempera- } \\
\text { tura }^{\circ} \mathrm{C}\end{array}$ & $\begin{array}{c}\text { Tempo de } \\
\text { reaçấo } \\
\text { (Horas) }\end{array}$ & pH & $\begin{array}{c}\text { Cond. } \\
\mu \mathrm{mho} / \mathrm{cm}\end{array}$ & $\mathrm{HCO}_{3}^{-}$ & $\mathrm{CO}_{3}^{2-}$ & $\mathrm{SO}_{4}^{2-}$ & $\mathrm{Cl}^{-}$ & $\mathbf{F}^{-}$ & $\mathrm{Na}^{+}$ & $\mathbf{K}^{+}$ & $\mathrm{Ca}^{2+}$ & $\mathbf{M g}^{2+}$ & $\mathrm{Si}^{4+}$ & $\mathrm{Al}^{3+}$ & $\begin{array}{c}\text { Mn } \\
\text { total }\end{array}$ & $\begin{array}{c}\text { Fe } \\
\text { total }\end{array}$ \\
\hline Ambiente & $\begin{array}{r}8 \\
24 \\
72 \\
168 \\
504 \\
1176\end{array}$ & $\begin{array}{c}7,84 \\
7,96 \\
7,99 \\
7,90 \\
- \\
8,05\end{array}$ & $\begin{array}{c}106 \\
106 \\
135 \\
153 \\
- \\
146\end{array}$ & $\begin{array}{c}42,0 \\
49,2 \\
55,8 \\
62,4 \\
- \\
100,5\end{array}$ & $\begin{array}{l}- \\
- \\
- \\
- \\
- \\
-\end{array}$ & $\begin{array}{c}10,2 \\
11,3 \\
12,1 \\
13,7 \\
- \\
27,4\end{array}$ & $\begin{array}{c}1,65 \\
1,73 \\
1,89 \\
2,40 \\
- \\
2,38\end{array}$ & $\begin{array}{c}2,54 \\
2,86 \\
3,28 \\
3,78 \\
- \\
4,20\end{array}$ & $\begin{array}{c}15,75 \\
17,75 \\
21,50 \\
25,50 \\
- \\
38,50\end{array}$ & $\begin{array}{c}3,49 \\
3,62 \\
3,63 \\
3,88 \\
- \\
20,90\end{array}$ & $\begin{array}{c}2,70 \\
3,40 \\
6,55 \\
3,60 \\
- \\
9,70\end{array}$ & $\begin{array}{c}0,08 \\
0,10 \\
0,10 \\
0,13 \\
- \\
0.41\end{array}$ & $\begin{array}{c}<2,0 \\
<2,0 \\
<2,0 \\
2,22 \\
- \\
2,77\end{array}$ & $\begin{array}{c}<0,5 \\
<0,5 \\
<0,5 \\
<0,5 \\
- \\
<0,5\end{array}$ & $\begin{array}{c}<0,05 \\
<0,05 \\
0,05 \\
<0,05 \\
- \\
0,06\end{array}$ & $\begin{array}{c}<0,05 \\
<0,05 \\
<0,05 \\
<0,05 \\
- \\
<0,05\end{array}$ \\
\hline $80^{\circ} \mathrm{C}$ & $\begin{array}{r}8 \\
24 \\
72 \\
168 \\
504 \\
1176\end{array}$ & $\begin{array}{r}7,93 \\
8,27 \\
8,02 \\
8,11 \\
- \\
7,26\end{array}$ & $\begin{array}{c}145 \\
212 \\
267 \\
340 \\
- \\
385\end{array}$ & $\begin{array}{c}72,8 \\
108,4 \\
125,5 \\
125,9 \\
- \\
32,1\end{array}$ & $\begin{array}{l}- \\
- \\
-\end{array}$ & $\begin{array}{c}12,5 \\
19,1 \\
23,4 \\
40,9 \\
- \\
121,1\end{array}$ & $\begin{array}{c}1,64 \\
2,10 \\
2,53 \\
3,69 \\
- \\
3,07\end{array}$ & $\begin{array}{c}3,66 \\
5,46 \\
6,63 \\
8,48 \\
-\overline{6,17}\end{array}$ & $\begin{array}{c}23,25 \\
41,75 \\
48,50 \\
66,25 \\
- \\
64,75\end{array}$ & $\begin{array}{r}6,00 \\
10,00 \\
8,75 \\
9,50 \\
- \\
6,00\end{array}$ & $\begin{array}{c}2,85 \\
4,06 \\
3,64 \\
3,34 \\
- \\
2,70\end{array}$ & $\begin{array}{r}0,06 \\
<0,05 \\
<0,05 \\
<0,05 \\
- \\
<0,05\end{array}$ & $\begin{array}{r}4,44 \\
1,29 \\
10,29 \\
8,0 \\
- \\
<2,0\end{array}$ & $\begin{array}{c}2,17 \\
3,7 \\
3,04 \\
1,74 \\
- \\
<0,5\end{array}$ & $\begin{array}{c}<0,05 \\
<0,05 \\
<0,05 \\
<0,05 \\
- \\
<0,05\end{array}$ & $\begin{array}{c}<0,05 \\
<0,05 \\
<0,05 \\
<0,05 \\
\quad- \\
<0,05\end{array}$ \\
\hline
\end{tabular}

Tipo de rocha: Material de preenchimento de veio

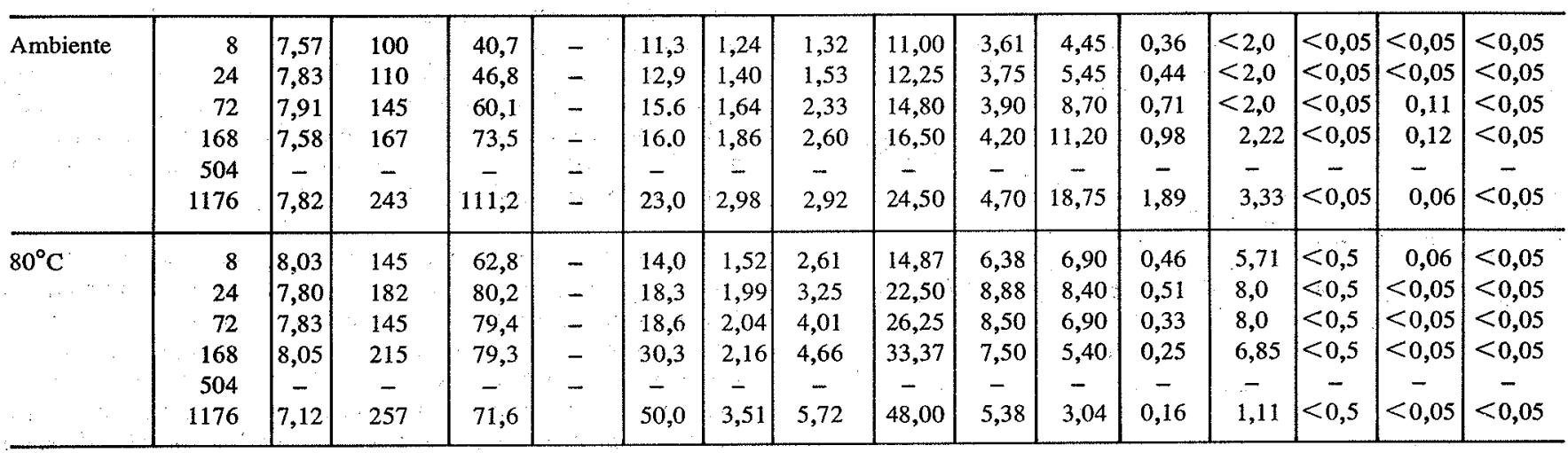

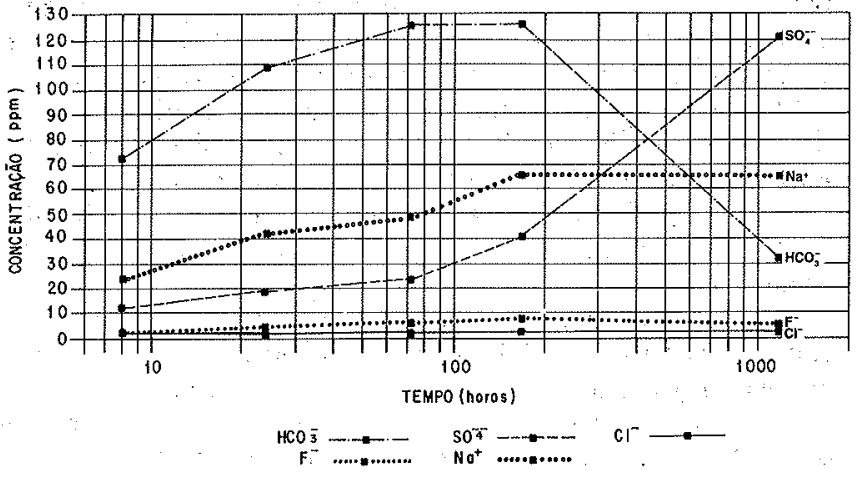

Figura 8 - Evolução das concentrações com o tempo de reação para as soluções em tinguaíto a $80^{\circ} \mathrm{C}$

Figure 8 - Evolution of the concentrations with reaction time for solutions in tinguaite under $80^{\circ} \mathrm{C}$

no fonólito $(<0,05 \mathrm{ppm})$, atingindo valores entre 0,6 e $7 \mathrm{ppm}$ no foiaíto e entre 1 e $3,7 \mathrm{ppm}$ no tinguaíto. $O$ silício atingiu valores mais altos nas soluçōes extraídas do foiaíto (de 2 a 12 $\mathrm{ppm}$ ), mostrando clara influência da temperatura, sem atingir um estado de equilíbrio e longe dos níveis de saturação, mesmo para o quartzo.

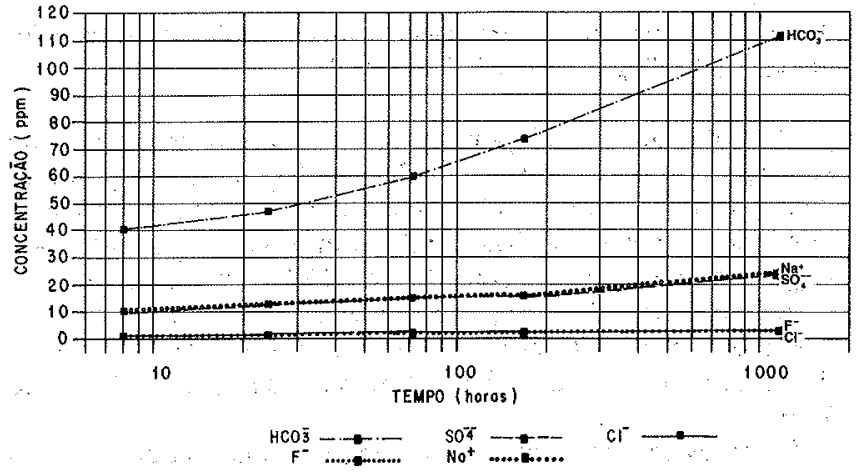

Figura 9 - Evolução das concentraçóes com o tempo de reaşão para as soluções em material de preenchimento de veio à temperatura ambiente

Figure 9 - Evolution of the concentrations with rection time for solutions in tinguaite under environmental temperature

Metais alcalinos e alcalino-terrosos Entre os metais alcalinos e alcalino-terrosos, o sódio foi o que mostrou maior mobilidade. A concentração deste elemento nas soluçóes mostra clara influência da temperatura e menor relação ao tipo de rocha. 
Tabela 6 - Total de sólidos dissolvidos nas soluções de reação após os ensaios.

Table 6 - Total dissolved solids in the reactions ofter the tests

\begin{tabular}{l|c|c|c|c|c|c}
\hline \multirow{2}{*}{$\begin{array}{c}\text { Tipo de } \\
\text { rocha }\end{array}$} & \multicolumn{2}{|c|}{$\begin{array}{c}\text { Solidos } \\
\text { dissolvidos } \\
(\mathbf{p p m})\end{array}$} & $\begin{array}{c}\text { Condutividade } \\
(\mu \text { mho/cm) }\end{array}$ & \multicolumn{2}{|c}{ pH } \\
\cline { 2 - 7 } & $\begin{array}{c}\text { Temp. } \\
\text { ambi- } \\
\text { ente }\end{array}$ & $\mathbf{8 0}{ }^{\circ} \mathrm{C}$ & $\begin{array}{c}\text { Temp. } \\
\text { ambi- } \\
\text { ente }\end{array}$ & $\mathbf{8 0}{ }^{\circ} \mathrm{C}$ & $\begin{array}{c}\text { Temp. } \\
\text { ambi- } \\
\text { ente }\end{array}$ & $\mathbf{8 0}{ }^{\circ} \mathrm{C}$ \\
\hline $\begin{array}{l}\text { Foiaíto (1) } \\
\text { Fonólito }\end{array}$ & 279,13 & 358,31 & 350 & 452 & 8,35 & 8,24 \\
$\begin{array}{l}\text { Tinguaíto (2) } \\
\text { Material de } \\
\text { preenchimento } \\
\text { de veio (2) }\end{array}$ & 206,82 & 235,89 & 146 & 385 & 8,05 & 7,26 \\
\hline
\end{tabular}

(1) Tempo de reação $=21$ dias

(2) Tempo de reação $=49$ dias

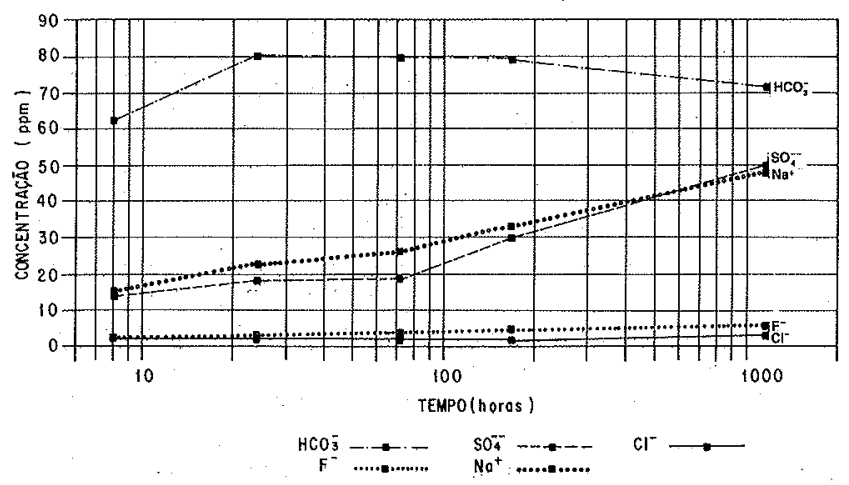

Figura 10 - Evolução das concentraçóes com o tempo de reação para as soluções em material de preenchimento de veio a $80^{\circ} \mathrm{C}$

Figure 10 - Evolution of the concentrations with reaction time for solutions in "filling vein material" under $80^{\circ} \mathrm{C}$

Do total de $21.200 \mathrm{ppm}$ de sódio contido nos $500 \mathrm{~g}$ de foiaíto, foram extraídos pela solucão $78 \mathrm{ppm}$, à temperatura ambiente, e $99 \mathrm{ppm}$, a $80^{\circ} \mathrm{C}$. No fonólito, a rocha de maior conteúdo de sódio $(25.745 \mathrm{ppm})$ foram liberados apenas $34 \mathrm{e}$ $58 \mathrm{ppm}$ à temperatura ambiente e a $80^{\circ} \mathrm{C}$, respectivamente.

No material de veio, com apenas $5.400 \mathrm{ppm}$ de $\mathrm{Na}$, extraíram-se 24 e $48 \mathrm{ppm}$. No tinguaíto, com $10.000 \mathrm{ppm}$ de $\mathrm{Na}$, foram obtidas de 36 a $64 \mathrm{ppm}$, mais que a obtida no fonólito.

O potássio, por outro lado, embora mais abundante na rocha que o sódio, tende a permanecer ou ser fixado nos produtos de alteração. $\mathrm{O}$ material alterado de preenchimento de veio mostra maior proporção de $K$ em relação às rochas frescas de foiaíto e tinguaíto, e uma menor proporção de sódio, indicando claramente esta tendência de mobilidade do sódio e fixação de potássio nos produtos de intemperismo ou de alteração hidrotermal.

Nas soluções de reação, nóta-se ainda uma influência da temperatura, mas as concentrações de potássio são aproximadamente as mesmas, independente do tipo de rocha, atingindo níveis de $5 \mathrm{ppm}$, à temperatura ambiente, e em torno de $10 \mathrm{ppm} \mathrm{a} 80^{\circ} \mathrm{C}$. Ao contrário do sódio, o potássio mostra certa tendência a um equilíbrio, além de indicar decréscimo da concentração com o tempo, sugerindo que parte dos íons liberados seria reabsorvido na superfície dos grãos da rocha.

A razão $\mathrm{Na} / \mathrm{K}$ no foiaíto é de 1,08 e no material do veio, de 0,204 . Nas soluçôes extraídas do foiaíto, a razão $\mathrm{Na} / \mathrm{K}$ varia de 18 a 27, à temperatura ambiente, enquanto no material de veio, de 5,1 a 8,8 .

Em relação ao cálcio, no qual o conteúdo nas rochas é aproximadamente semelhante (11.700 ppm no foiaíto a 8.200 ppm no fonólito), a quantidade máxima liberada alcançou 18,7 ppm na solução do material de veio, e é menor que $10 \mathrm{ppm}$ para as demais rochas; nâo havendo relaçāo direta com o conteúdo deste elemento nas rochas. Observou-se também, em todos os ensaios, um decréscimo de concentração de cálcio com o aumento da temperatura; este fato concorda com a constatação de que o conteúdo em cálcio da maioria das fontes termais é muito baixo, em relação aos álcalis, como conseqüência da baixa solubilidade do carbonato de cálcio (e também do magnésio), em altas temperaturas (Garrel \& Dreyer 1952, White 1957, Mahon 1973).

O conteúdo de magnésio nas soluções de reação, por outro lado, não mostrou nenhuma relação com o tipo de rocha, tendo um comportamento algo semelhante ao do cálcio. Em todos os experimentos, as concentrações, em geral, não ultrapassam a $0,50 \mathrm{ppm}$, sendo não-detectáveis $(<0,5 \mathrm{ppm})$ nas soluções à temperatura de $80^{\circ} \mathrm{C}$. Apenas nas provenientes do material alterado de veio a concentração de $\mathrm{Mg}^{2+}$ atingiu um máximo de 1,89 ppm.

A razão $\mathrm{Ca} / \mathrm{Mg}$ no foiaíto é de 4,64, igual ao do material de veio. Nas soluções variaram de 16,8 a 10,3 , no foiaíto, e de 7,4 a 6 no material de veio, à temperatura ambiente, indicando a maior velocidade de reação do cálcio no estágio inicial, diminuindo progressivamente com o tempo.

Os elementos aniônicos As concentrações de cloreto nas soluções de reação variaram de $2,38 \mathrm{ppm}$ no tinguaíto, à temperatura ambiente, até um máximo de $10,42 \mathrm{ppm}$, a $80^{\circ} \mathrm{C}$, no fonólito. Há, em geral, pequeno incremento de $\mathrm{Cl}^{-}$nas soluções, com a temperatura, em todos os tipos de rocha, à exceção do foiaíto, no qual a concentração deste elemento foi maior à temperatura ambiente do que a $80^{\circ} \mathrm{C}$. A velocidade de reação é rápida (nos primeiros um a três dias) tendendo para um lento incremento ou estabilização até o final do experimento. Apenas no fonólito observou-se uma elevação gradual na concentração deste elemento. $\mathrm{A}$ razâo $\mathrm{Cl} / \mathrm{F}$ varia de 0,20 a 0,75 nas soluções provenientes do foiaíto, tinguaíto e material de veio, enquanto nas do fonólito varia de 0,75 a 1,14. De um modo geral, observa-se uma tendência a um decréscimo da razão do início ao tempo final da reação, indicando maior velocidade de reação do fluoreto.

$\mathrm{O}$ total de $\mathrm{F}^{-}$contido nas rochas é de $1.064 \mathrm{ppm}$ no foiaíto; 1.032 no fonólito; 1.066 no material de veio; e 3.542 no tinguaíto.

As concentrações de fluoreto extraídas das rochas nas soluções variaram de $2,9 \mathrm{ppm}$ (material de veio, à temperatura ambiente) a um máximo de $13,42 \mathrm{ppm}$ (foiaíto a $80^{\circ} \mathrm{C}$ ). Esta proporção corresponde a apenas $0,27 \%$ e $1,26 \%$ da quantidade total de $\mathrm{F}^{-}$contido na rocha. Para todos os tipos de rochas; há uma clara influência da temperatura na solubilizaçâo deste elemento, Tanto à temperatura ambiente quanto a $80^{\circ} \mathrm{C}$, o tempo não foi suficiente para as concentrações de fluoreto atingirem o equilíbrio ou saturação. Apenas no experimento com foiaíto, à temperatura ambiente, o fluoreto alcançou uma concentração de $10,73 \mathrm{ppm}$, acima, portanto, da solubilidade do fluoreto de cálcio, em água pura, a $25^{\circ} \mathrm{C}(8,7 \mathrm{ppm})$. Na solução a $80^{\circ} \mathrm{C}$ procedente do tinguaíto, ocorreu uma elevaçấo đe concentração de fluoreto, após sete dias $(8,48 \mathrm{ppm})$, decrescendo, após 49 dias, ao nível inicial correpondente a três dias $(6,17 \mathrm{ppm})$. Este fato tem sido observado em experimentos a altas temperaturas realizados por Mahon (1973) e Ellis \& Mahon (1964), que atribuem a concentrações metaestáveis de fluoreto. 
As concentrações de sulfato nas soluções variam de 14,8 ppm (fonólito, à temperatura ambiente) a 121 ppm (tinguaíto a $80^{\circ} \mathrm{C}$ ). Em todas as amostras não foi alcançado um estado de equilíbrio, mas, à temperatura ambiente, a velocidade de reação é lenta e progressiva enquanto a $80^{\circ} \mathrm{C}$ é mais rápida.

$\mathrm{O}$ enxofre total contido nas rochas varia de $0,06 \%$ nos fonólitos e material de veio a $0,11 \%$ no foiaíto, o que equivale a 300 e $500 \mathrm{ppm}$ nas amostras utilizadas nos testes. Tais quantidades dariam um total de 450 a $750 \mathrm{ppm}$ de $\mathrm{SO}_{4}^{2-}$, se todo o enxofre fosse oxidado e extraído das rochas, valores estes inferiores à solubilidade de $\mathrm{SO}_{4} \mathrm{Ca}$ em água, que é de $1.500 \mathrm{ppm}$. As quantidades de enxofre extraídas das rochas em forma de sulfetos correspondem a apenas $1,64 \%$ e $7,33 \%$ do total contido na rocha.

Considerando-se que as condições em que foram realizados os testes permitiram fornecimento contínuo de oxigênio, pode-se concluir que o sulfato provém unicamente da oxidação de sulfetos contidos nas rochas. Ellis \& Mahon (1964) em testes de reatividade de rochas vulcânicas têm encontrado valores mais altos de $\mathrm{SO}_{4}^{2-}$ em temperaturas mais baixas, devido a sua instabilidade sob alta temperatura. Nos atuais experimentos, em temperaturas não muito elevadas $\left(80^{\circ} \mathrm{C}\right)$, observou-se um aumento das concentrações de $\mathrm{SO}_{4}^{2-}$ em relação às obtidas em temperatura ambiente.

As concentraçōes de bicarbonato nas soluçốes variaram de $27,8 \mathrm{ppm}$ no tonólito (à temperatura ambiente e após oito horas de reação) a um máximo de $147,7 \mathrm{ppm}$, no foiaíto (à temperatura ambiente e após 21 dias de reação). Em todos os experimentos, a concentração de $\mathrm{HCO}_{3}^{-}$, ao final do período de duração dos testes, foi menor à temperatura de $80^{\circ} \mathrm{C}$ que à temperatura ambiente, como conseqüência da menor solubilidade de $\mathrm{CO}_{2}$, e paralelamente a de $\mathrm{CaCO}_{3}$, ao aumentar a temperatura.

A água pura deixada saturada com o $\mathrm{CO}_{2}$ contido no ar pode chegar a dissolver de 50 a $75 \mathrm{ppm}$ de $\mathrm{CaCO}_{3}$ e, se tem sais dissolvidos, pode atingir até $100-125 \mathrm{ppm}$ por causa do efeito da força iônica (Custódio \& Llamas 1976).

Nas soluções de reação, à temperatura ambiente, observou-se em todos os experimentos aumento progressivo da concentração até $90-147 \mathrm{ppm}$. Nas soluções a $80^{\circ} \mathrm{C}$ verificou-se rápido aumento da concentração de bicarbonato até níveis de $80-165 \mathrm{ppm}$, após sete dias de reação, ocorrendo então precipitação de $\mathrm{CO}_{3} \mathrm{Ca}$ e diminuição de $\mathrm{pH}$.

Os experimentos indicaram que a hidrólise dos silicatos é um fenômeno rápido, ajudado pela presença de $\mathrm{CO}_{2}$, provocando aumento de $\mathrm{pH}$ e liberação de cảtions da estrutura cristalina dos minerais das rochas.

Relações com a composição das águas subterrâneas $\mathrm{Na}$ tabela 7 apresenta-se um resumo das variações de composição química das soluções de reaçẫo para os quatro tipos de rochas utilizados nos ensaios, incluindo os valores máximos e mínimos obtidos à temperatura ambiente e a $80^{\circ} \mathrm{C}$.

Uma comparação entre esses resultados experimentais e as águas subterrâneas da região mostra, essencialmente, os seguintes aspectos:

1. As soluçōes de reação, à temperatura ambiente, apresentam um maior grau de mineralização do que as águas das nascentes e fontes frias da região. Mesmo comparando-se a composição das soluções, após oito horas de imersão, ainda assim alguns elementos como sodio, sulfato e fluoreto mostram concentrações mais elevadas.

Isto evidencia que as águas das fontes frias e nascentes, embora pouco profundas, de trânsito rápido, mais ácidas e agressivas, são menos mineralizadas por circularem em um manto de alteração já bastante lixiviado.

2. Há uma correspondência muito grande entre as soluções experimentais, à temperatura ambiente, e as águas subterrâneas da zona intermediária, em especial às provenientes de poços mais profundos. A única diferença é a
Tabela 7 - Resumo das variaçóes de composição das soluções de reação para os quatro tipos de rochas utilizadas nos ensaios (em ppm)

Table 7 - Sumary of the composition variations of the reaction solution to the four kinds of rocks used in the tests

\begin{tabular}{|c|c|c|c|c|}
\hline Determinações & $\begin{array}{l}\text { Tempe } \\
\text { amb }\end{array}$ & $\begin{array}{l}\text { eratura } \\
\text { jiente }\end{array}$ & & $0^{\circ} \mathrm{C}$ \\
\hline $\mathrm{pH}$ & 7,4 & $-\quad 8,5$ & 7,1 & $-\quad 8,27$ \\
\hline $\begin{array}{l}\text { Condutividade em } \\
\mu \mathrm{mho} / \mathrm{cm}\end{array}$ & 66 & -350 & 62 & -385 \\
\hline $\mathrm{Ca}^{2+}$ & 1,6 & $-\quad 18,7$ & 0,51 & 8,4 \\
\hline $\mathrm{Mg}^{2+}$ & $<0,05$ & $-\quad 1,89$ & $<0,05$ & 0,5 \\
\hline $\mathrm{Na}^{+}$ & 11,0 & $-\quad 78,0$ & 14,8 & $-\quad 99,5$ \\
\hline $\mathrm{K}^{+}$ & 2,05 & $-\quad 20,9$ & 3,49 & $-10,5$ \\
\hline $\mathrm{HCO}_{3}^{-}$ & 27,8 & $-147,7$ & 32,1 & $-165,9$ \\
\hline $\mathrm{CO}_{3}^{2-}$ & 0 & $-\quad 3,24$ & & - \\
\hline $\mathrm{Cl}^{-}$ & 1,2 & $-6,2$ & 1,5 & $-\quad 10,6$ \\
\hline $\mathrm{SO}_{4}^{2-}$ & 8,2 & $-\quad 27,4$ & 11,3 & $-121,1$ \\
\hline $\mathrm{F}^{-}$ & 1,1 & $-10,73$ & 1,7 & $-13,4$ \\
\hline Fe (total) & $<0,05$ & $-\quad 0,2$ & 0,05 & 0,26 \\
\hline $\mathrm{Si}^{4+}$ & $<2,0$ & $-\quad 5,0$ & 1,1 & $-\quad 12,0$ \\
\hline
\end{tabular}

provenientes de poços mais profundos. A única diferença é a concentração de sulfato, muito baixa nas águas subterrâneas, devido à ausência de oxigênio em profundidade que impede a oxidação de sulfetos.

3. Em relação às águas termais de circulação profunda observa-se nestas uma maior mineralização, com concentrações de $\mathrm{HCO}_{3}^{-}, \mathrm{Na}^{+}$e $\mathrm{F}^{-}$mais elevadas e um caráter mais alcalino, devido ao maior tempo de contato água-rocha e elevada pressão em profundidade, nas condições naturais. A correspondência entre os demais constituintes obtidos nas soluções experimentais a $80^{\circ} \mathrm{C}$ mostra que as águas termais adquiriram sua composição pelos simples processos de lixiviação das rochas durante seu percurso subterrâneo. $O$ modelo de evolução química das águas em profundidade, tal como se definiu, mostra grande concordância com os resultados obtidos por meio das soluçōes experimentais em laboratório.

CONCLUSÕES Há grande correspondência entre a composição das águas subterrâneas e a composição das soluçōes de reaçōes obtidas em laboratório para quatro tipos de rochias representativas da regiấo de Poços de Caldas.

- As reaçóes de hidrólise e os processos de solubilização dos contituintes das rochas ocorrem em tempo muito rápido. $\mathrm{O}$ foiaíto foi a rocha mais reativa, seguida do tinguaíto e, em menor proporção, o fonólito e o material alterado de preenchimento de veio.

- Os processos geológicos que atuaram na formação do complexo alcalino de Pocos de Caldas - intrusão alcalina, atividade vulcânica e fase hidrotermal - foram muito favoráveis a uma ampla disseminacão de minerais contendo flúor. $\mathrm{O}$ enriquecimento em fluoretos das águas subterrâneas com a profundidade deve-se à dissolução da própria rocha e do material das paredes das fraturas, na qual o aumento de temperatura da água contribui para intensificar o processo. 


\section{REFERÊNCIAS BIBLIOGRÁFICAS}

ALMEIDA, F.F.M. DE. 1967. Origem e evoluçâo da plataforma brasileira. DNPM-DGM, Rio de Janeiro. 36p. (Bol. $\mathrm{n}^{\circ}$.241).

AMARAL, G. et al. 1967. Potassium-argon ages of alkaline rocks from southern Brazil. Geoch. Cosmoch. Acta, 31:117-142.

ARAUJO, R.L.C. 1980. Pesquisa geotermal na chaminé alcalina de Pocos de Caldas. In: CONGR.BRAS.GEOL. 31, Baln. Camboriú, 1980. Anais... Baln. Camboriú, SBG, v.2., p.1059-74

BJORNBERG, A.J.S. \& LANDIM, P.M.B. 1966. Sobre os arenitós da Serra da Mantiqueira e os arenitos da Formação Botucatu (Eocretáceo). Bol. Paranaense de Geografia (18-20):19-24.

CRUZ, W.B. da et al. 1987. Avaliaçâo hidrogeológica $e$ hidrogeoqut́mica das águas subterrâneàs dos arredores de Poços de Caldas. Inédito. Cetec, Belo Horizonte.

CUSTÓDIO, E.G. 1974. Contribuiciones al conocimiento geohidroquímico de la Isla Lanzarote (Islas Canarias, España). In: SIMP. INTERN. SOBRE HIDROLOGÍA DE TERRENOS VOLCÁÁNICOS. Actas... Gobierno Español-UNESCO-PNUD.

CUSTÓDIO, E.G. \& LLAMAS, M.R. 1976. Hidrología subterránea. Ediciones Omega S/A. $1^{\text {a }}$ ed., Barcelona.

ELLIS, A.J. 1973. Chemical processes in hydrothermal system review. In: SYMPOSIUM ON HYDROGEOCHEMISTRY AND BIOGEOCHEMISTRY, Tokio, Japan, 1973. Praceedings... Tokio. v.l.

ELLIS, A.J. \& MAHON, W.A.J. 1964. Natural hydrothermal system and experimental hot-water/rock interactions. Geoch.Cosmoch. Acta, 28:1323-1357.

GARRELS, R.M. \& DREYER, R.M. 1952. Mechanism of limestone replacement at low temperatures and pressures. Geol.Soc. America Bull., 63:325-379.

GORSKY, V.A. \& GORSKY, E. 1970. Diferentes tipos de mineralizaçă̄o no planalto de Poços de Caldas, MG. In: CONGR.BRAS.GEOL., 24, Brastlia, 1970. Res.Conf. e Comunicaçöes ... Bol.Esp. 1, SBG. p.135-137.

HURTER, S.J. et al. 1983. Coleção brasileira de dados geotérnicos Série 2-Fontes Termais. Sâo Paulo. (Pub. IPT n⿳01233).

LEONARDOS, O.H.; FYFE, W:S. \& KROMBERG, B. s.n.t. Rochagem: método de aumento de fertilidade em solos lixiviados e arenosos.
MAHON, W.A.J. 1973. The chemical composition of natural thermal waters. In: SYMPOSIUM ON HYDROGEOCHEMISTRY AND BIOGEOCHEMISTRY, Tokio, Japan, 1973. Proceedings... Tokio. v.I:

MINAMI, E.A.; YAMADA, H.; OSSAKA, T.; HIRABAYASHI, J. OHIRA, Y. 1973. Experimental studies on the reaction between rocks and hot surings. In: SYMPOSIUM ON HYDROGEOCHEMISTRY AND BIOGEOCHEMISTRY, Tokio, Japan, 1973. Proceedings... Tokio. v.1, p.153-164.

NABOKO, S.I. \& SILNICFENKO, V.G. 1960. The problem of matemosphism on the interation of hidrotermal solutions and vulcanic rocks. Volcanological Lab., USSR Academy of Sciences, (18): $123-133$

PENTCHEVA, E.N. 1972. Sur la rôle de l'interaction "eau-rocha" pour la migration des oligoelements caracteristiques pour les eaux thermales à azote In: INTERN.SYMP. ON PROTECTION OF MINERAL WATERS, Karlovy Vary, 1972. Proceedings... Assoc.Int.Hydrogeologiques. p. 245-253.

PORTILHO, M. \& LEONARDOS, O.H. 1976. $\mathrm{pH}$ de abrasāo em rochás e sua aplicáção na agricultura. Recife. Bol.Mineralógico, n' 4 .

SPEARS, D.A. 1974. Relationship between water-solubre cations and paleosalinity. Geoch.Cosmoch. Acta, 38:567-575.

SZALAY, A. \& SANSONI, Z. 1973. Investigation on the leaching of uranion from crusched magmatic rocks. In: SYMPOSIUM ON HIDROGEOCHEMISTRY AND BIOGEOCHEMISTRY, Tokio, Japan, 1973. Proceedings... Tokio. v.I, p.261-272.

WHITE, D.E. 1957. Thermal waters of volcanic origin. Geol.Soc. America Bull., (68):1637-1958.

ZAMBERLAN, E, \& VIANA, R.A. 1985. Reabilitação de área minerada de xisto. In: CONGR.BRAS. MIN. 1, Brasília, 1985. Coletânea de trabalhos Técnicos... Jbram.

MÁNUSCRITO 539

Recebido em 06 de maio de 1988

Revisão recebida em 16 de novembro de 1988

Revisẫo aceita em 18 de novembro de 1988

.. a progressiva contaminação dos sedimentos pode dar lugar a problemas crónicos e graves. Isto deve servir de alerta aos orgãos fiscalizadores que, na maioria das vezes, monitoram o mercúrio apenas na coluna d'água, ignorando que é no sedimento que se localiza o maior problema.

Wilson F. Jardim, 1988, contaminação por mercúrio: fatos e fantasias, Ciência Hoje, 7(41): p 78. 